\title{
EXPANSÃO URBANA E CONFLITO AMBIENTAL: UMA DESCRIÇÃO DA PROBLEMÁTICA DO MUNICÍPIO DE MOSSORÓ, RN - BRASIL
}

\author{
The urban sprawl and environmental conflict: \\ brief description of the problem of Mossoró, RN (Brazil)
}

\author{
Maria Clara Torquato Salles \\ Mestranda em Ciências Naturais, Universidade do Estado do Rio Grande do Norte - UERN \\ mariaclaratorquato@hotmail.com \\ Alfredo Marcelo Grigio \\ Prof. Adjunto, Depto. de Gestão Ambiental - UERN, Mossoró \\ grigioma@yahoo.com \\ Márcia Regina Farias da Silva \\ Geógrafa, Prof. Adjunta, Depto. de Gestão Ambiental, UERN, Mossoró \\ marciaregina@uern.br
}

Artigo recebido em 06/02/2012 e aceito para publicação em 23/02/2013

RESUMO: Os ambientes naturais são constantemente transformados e utilizados para os processos de expansão e urbanização, para a criação dos ambientes artificiais, com isso, ocorre nos solos urbanos fortes implicações sociais e ambientais que implicam diretamente para as situações de risco e vulnerabilidade. Com isso traz-se a importância de estudar, conceituar e caracterizar as relações do ambiente urbano, especificamente as do município de Mossoró (RN). É importante destacar que o município possui um grande potencial para o desenvolvimento econômico com a interação entre elementos de diversos setores econômicos, já que o mesmo nos últimos anos vem passando por um momento de grande dinamismo nos processos de ocupação do espaço urbano e consequentemente vários problemas e impactos decorrentes desse processo de expansão urbana. Onde se sugere o uso de políticas públicas e sociais, com maior efetividade em ações de monitoramento, fiscalização e punição a atividades e processos que possam comprometer a qualidade socioambiental do município, além da participação da sociedade, e ainda da necessidade de ser elaborado o zoneamento ecológico econômico do município que irá servir de instrumento de ordenação do território e auxilio ao planejamento

Palavras chaves: Solo urbano; Expansão; Vulnerabilidade; Zoneamento.

\begin{abstract}
The Natural environments are constantly transformed and used for the expansion and urbanization processes, for the creation of artificial environments; it occurs in urban soils strong social and environmental implications that directly affect to the situations of risk and vulnerability. This brings up the importance of studying, conceptualizing and characterizing the relationship of the urban environment, more specifically the city of Mossoró (RN). Importantly, the city has a great potential for economic development with the interaction between elements of various economic areas, the same as in recent years has been going through a time of great dynamism in the process of occupation of urban space and therefore various issues and impacts of this process of urban sprawl. Where it suggests the use of public and social pol icies, with greater effectiveness in monitoring actions, enforcement and punishment processes and activities that may compromise the quality of the municipality socio-environmental, addition to the participation of society, and yet the need to be prepared the economic zoning of the municipality that will serve as an instrument of regional planning and assisting in planning.
\end{abstract}

Keywords: Urban Land; Expansion; Vulnerability; Zoning. 


\section{INTRODUÇÃO}

Com o processo de dominação, expansão e urbanização, o homem transformou e transforma ambientes naturais, para criar os ambientes artificiais, ou seja, o meio ambiente urbano, para o atendimento das suas necessidades como ser social. Com isso traz-se a importância de estudar, conceituar e caracterizar as relações do ambiente urbano, para que se possa contribuir para a discussão da melhoria da qualidade de vida dentro das aglomerações urbanas e dos problemas socioeconômicos e ambientais existentes.

Um aspecto que vem sendo discutido na atualidade é a percepção dos riscos e dos conflitos ambientais existentes no meio ambiente urbano. Nesse meio interagem diferentes seres vivos, e é onde indivíduos, grupos e comunidades humanas diversas convivem com as dinâmicas: econômica, política social e cultural. Esse modo de vida da sociedade contemporânea, atualmente, vem sendo responsáveis por influências diretas e indiretas na quantidade, qualidade, variedade dos recursos disponíveis, ocasionando a valorização e revalorização do solo, produção, expansão, potencialidades, usos, manifestações, ocupações, trocas, trabalho, infraestrutura, entre outros fatores positivos e negativos.

Com a finalidade de buscar possíveis respostas a respeito do processo de ocupação e expansão do meio urbano da cidade de Mossoró, Rio Grande do Norte, e considerando as especificidades relacionadas a essa problemática, optou-se por realizar um estudo com bases teóricas e históricas sobre a temática de expansão urbana e os conflitos ambientais existentes no meio urbano. Será também exemplificado esse processo através de descrições locais, utilizando-se como modelo o caso da zona urbana do município supracitado. Afim de, evidenciar os conflitos e problemas existentes a partir do processo de crescimento urbano, especificamente, as questões ambientais.

É importante destacar que o município de Mossoró possui um grande potencial para o desenvolvimento econômico com a interação entre elementos de diversos setores econômicos, sendo possível destacar como principais atividades econômicas significativas: a petrolífera, salineira, fruticultura irrigada, industrial, alimentícia, habitacional, artefatos cerâmicos, mineração, além da forte pressão sobre o meio ambienta exercida pelo processo de urbanização sem planejamento. Atualmente esse desenvolvimento econômico acelerado e crescente na cidade vem ganhando um amplo destaque na mídia nacional, como por exemplo, referências em duas edições da Revista Veja dos dois últimos anos.

A primeira foi na edição $n^{\circ} 2180$ - ano $43-n^{\circ}$ 35 , de 01 de setembro de 2010 onde teve destaque em uma material denominada "Especial Cidades Médias" que tratou sobre a expansão e desenvolvimento econômico de vinte e três cidades brasileiras (consideradas entre 100.000 a 500.000 habitantes), onde apresenta que no Brasil existem cerca de duzentas e trinta e três cidades médias e que as mesmas abrigam $24 \%$ da população brasileira, consideradas como motores do progresso brasileiro. Onde nessa edição considera Mossoró como uma metrópole do futuro, pois o mesmo já chegou nessa localidade, com uma boa rede de serviços públicos e referida como um pólo na região oeste do estado de desenvolvimento e de serviços.

Já a segunda foi no ano de 2011, onde houve a outra reportagem da revista, a edição $\mathrm{n}^{\circ} 2241$ - ano 44 - $\mathrm{n}^{\circ} 44$, de 02 de novembro, onde Mossoró volta a ser destaque novamente na matéria denominada "Especial Cidades" Onde o vento sopra a favor com os municípios que fizeram as escolhas corretas para crescer e enriquecer prosperam rapidamente que agora apresenta as cidades campeãs de riqueza e de bem-estar, e destacam que Mossoró rompeu o ciclo da miséria e o aquecimento do setor imobiliário, de ofertas de mão-de-obra e aumento da renda per capita dos moradores.

\section{PREOCUPAÇÕES COM O USO E A OCUPAÇÃO DO SOLO URBANO: UM BREVE HISTÓRICO}

Os processos dinâmicos e históricos de uso e ocupação do solo urbano têm fortes implicações sociais e ambientais e implicam diretamente para as situações de risco e vulnerabilidade social e ambiental. Não é de hoje que estudos e pareceres já alertavam e indicavam as graves consequências a serem presenciadas e acometidas decorrentes do processo de evolução e de expansão das populações nos centros urbanos. De acordo com Costa e Peixoto (2007) os grupos sociais 
envolvidos nas transformações sociais e espaciais no meio urbano, contribuíram para o aumento dessas problemáticas representando interesses difusos dentro de um contexto especifico e colaborando para as disparidades sociais.

Nos âmbitos, global-nacional baseado em Dias (2009) estabelece ser possível sintetizar movimentos e declarações que ocorreram pelo mundo a fim de alertar os gestores e a população sobre o crescimento das cidades e suas consequências, como também ocorreram perspectivas de desafios a serem enfrentados para as cidades e o processo de consolidação do urbanismo como: A carta de Atenas que data de 1933 foi resultado das discussões ocorridas durante o IV Congresso Internacional de Arquitetura Moderna (CIAM), que se refere à Cidade Funcional e já apresentava a necessidade da separação de áreas residenciais, de lazer e de trabalho no meio urbano; o Relatório da Comissão Mundial de sobre Meio Ambiente e Desenvolvimento "Nosso Futuro Comum" publicado em 1987 indicava sobre o aumento e a busca das populações para o meio urbano e consequentemente a ocorrência de problemas de degradação, decadência e desequilíbrio com relação ao homem-natureza; a Agenda Habitat de 1996 decorrente da Segunda Conferência Global para os Assentamentos Humanos (Habitat II) é um documento aprovado por consenso pelos países participantes da conferência, os quais se comprometeram a implementar, monitorar e avaliar os resultados do seu Plano Global de Ação; a Constituição Federal de 1988 que contempla o desenvolvimento urbano em dois artigos específicos o Art. 182 e Art. 225; posteriormente a Lei de $n^{\circ} 10.257$, de 10 de julho de 2001, que estabelece normas de ordem pública e interesse social onde regulam o uso da propriedade urbana em prol do bem coletivo, da segurança e do bem-estar dos cidadãos, bem como do equilíbrio ambiental denominada Estatuto da Cidade.

Ademais, Santos (2009) apresenta no âmbito nacional que na década de 1950 foi criada a Superintendência de Desenvolvimento do Nordeste (SUDENE) com o objetivo de estimular a industrialização como forma de superar as dificuldades econômicas e impulsionar um planejamento estratégico de expansão capitalista no Brasil, fazendo migrar o capital produtivo do Centro-Sul para o Nordeste, incentivando a vinda de grandes grupos empresariais para cidade menores através de incentivos fiscais.

Na década de 1970 no Brasil foi implementado o Programa de Cidades Médias de abrangência nacional, o qual resultou de uma iniciativa da Comissão Nacional de Regiões Metropolitanas e Política Urbana para a implementação do planejamento urbano local. Como também o Sistema Financeiro de Habitação (SFH) e o Banco Nacional de Habitação (BNH) a serem responsáveis pelo desenvolvimento urbano das cidades brasileiras (ROCHA, 2005).

Em suma, esses agentes financeiros e programas trouxeram para as cidades em que se instalaram contribuições e avanços como: equipamentos urbanos, projetos de melhoria do espaço, conjuntos habitacionais, pavimentação de ruas e avenidas, arborizações, instituições de ensino, agências bancárias, serviços especializados, empreendimentos de iniciativa privada, entre outros. Por conseguinte, esses processos de urbanização contribuíram fortemente para o crescimento das cidades, o desenvolvimento econômico e para mudanças significativas na sociedade.

\section{METODOLOGIA}

O presente artigo é parte de uma dissertação de mestrado desenvolvida junto ao Programa de Pós-Graduação em Ciências Naturais da UERN. As fontes de pesquisa utilizadas como referências para o desenvolvimento do trabalho foram: levantamentos bibliográficos a partir de literatura especializada, referente às temáticas sobre cidades, expansão urbana e conflitos ambientais; pesquisas documentais; busca ao banco de dados e de imagens do Núcleo de Estudos Socioambientais e Territoriais - NESAT; o Plano Diretor; o Código de Obras, Posturas e Edificações; a Lei orgânica e o Código de Meio Ambiente do município de Mossoró (RN).

Durante a pesquisa foram realizadas leituras de materiais para embasamento teórico e de discussões, na tentativa de refletir sobre os problemas ambientais decorrentes da expansão urbana, partindo de uma análise teórica global-local sobre o histórico e a dinâmica das preocupações com o uso e ocupação do solo urbano, os conflitos e problemas ambientais no ambiente urbano, na área de estudo, e a necessidade 
do planejamento urbano nos municípios, tendo como exemplo breves descrições do município.

\section{CARACTERIZAÇÃO GEOGRÁFICA DO MU- NICÍPIO DE MOSSORÓ}

Situada na mesorregião Oeste do estado do Rio Grande do Norte, o referido município está localizado entre as capitais Natal/RN e Fortaleza/CE (figura 01). Nos últimos anos vem passando por um momento de grande dinamismo nos processos de ocupação do espaço urbano, que pode ser vislumbrado através da observância do rápido crescimento. De acordo com IBGE (2010) a cidade possui uma população de aproximadamente 259.815 habitantes, sendo eles 237.241 habitantes na zona urbana e 22.574 habitantes na zona rural. E ainda baseado nos dados IBGE (2010) o município conta com uma área territorial de 2.099,328 Km², equivalente a mais de $4,00 \%$ da superfície estadual, densidade demográfica de 123,76 (hab/ $\left.\mathrm{Km}^{2}\right)$ e com base nos dados da Prefeitura Municipal de Mossoró (2010) possui 52,83 $\mathrm{Km}^{2}$ de zona urbanizável e 60,33 $\mathrm{Km}$ de perímetro urbano.

Figura 01. Mapa de localização do município de Mossoró - RN/Brasil.

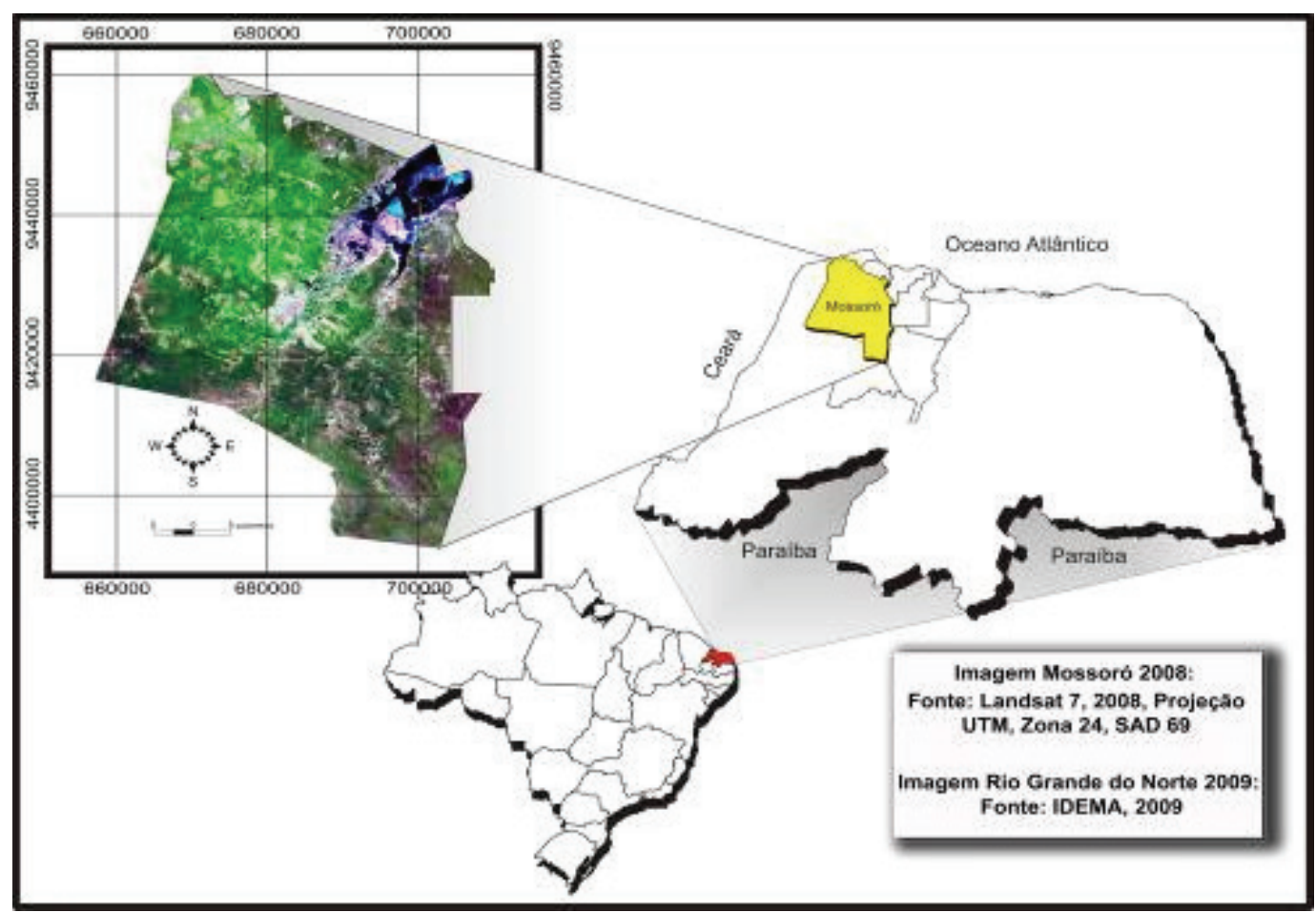

Fonte: Banco de dados do NESAT, 2011. Elaborado por Luiz Tarvernard de Souza Neto, 2009.

A expansão de Mossoró vem apresentando algumas características da urbanização recente, materializada em termos espaciais em processos de fragmentação e dispersão do tecido urbano, associados a mecanismos de crescente segregação socioespacial. Tornando-se necessários instrumentos técnicos políticos de regulação e de fiscalização.

A respeito da regulação do parcelamento do solo o município teve a necessidade de uma norma- tização que disciplinasse a organização do espaço que serão delineadas no parágrafo abaixo, fixando diretrizes para todas as construções, objetivando dotar a cidade de condições favoráveis de habitação, meios de circulação, locais de trabalho e lazer, de forma harmônica e em consonância com a conservação de locais paisagísticos e edificações de valor histórico e/ ou cultural. 
Assim a Prefeitura Municipal de Mossoró tem como instrumentos técnicos - políticos, Gerências e Secretárias como, por exemplo: a Secretaria Municipal do Desenvolvimento Territorial e Ambiental; a Gerência Executiva da Gestão Ambiental e a Gerência Executiva do Desenvolvimento Urbanístico. Ainda conta com legislação ambiental e urbanística vigente tais como: A lei complementar n. ${ }^{\circ} 012 / 2006$ que dispõe sobre o Plano Diretor do Município de Mossoró e dá outras providências; lei complementar $n^{\circ} 47 / 2010$ que dispõe sobre o Código de Obras, Posturas e Edificações do Município de Mossoró; lei orgânica de Mossoró de 03 de abril de 1990; lei complementar ${ }^{\circ}$ 026/2008 que institui o Código de Meio Ambiente, fixa a política municipal de meio ambiente e cria o Sistema Municipal do meio ambiente do município de Mossoró.

O município está inserido na Bacia do Rio Apodi-Mossoró e destaca-se com diversas atividades econômicas, sendo elas: agropecuária, extração de petróleo e gás natural, sal marinho, fruticultura irrigada, extração mineral (onde possui várias fábricas dentre elas a de cimento, de cerâmica, de cal, brita, etc.), indústrias de pequeno, médio e grande porte (dentre elas produtos de limpeza e produtos alimentícios) processamento de castanha de caju, extrativismo vegetal, comércio local, etc. Nos últimos anos o município vem passando por um intenso aquecimento no setor habitacional e potencial turístico com uma vasta variedade de rede hoteleira aqui instalada, águas termais, entre outras potencialidades.

\section{CONFLITOS E PROBLEMAS AMBIENTAIS NO AMBIENTE URBANO}

As cidades estão em processos contínuos de construção, influenciadas por desordens em torno do uso e da ocupação do solo urbano, conflitos socioambientais, injustiças e exclusões. Onde existem interesses, pressões e disputas quanto a esse uso e apropriação do solo e dos recursos disponíveis. Paralelamente convivem no mesmo ambiente da "cidade" problemas como os baixos padrões de vida, conflitos e ocupações em áreas vulneráveis, e altos padrões de vida e os desperdícios de consumo. Representando assim diversos desejos e interesses em um único am- biente. As políticas ambientais surgem decorrentes das pressões e tensões pelo meio existentes entre a sociedade e os gestores públicos (COSTA; BRAGA, 2002).

As ações antropicas provocadas pelos seres humanos são responsáveis pela degradação do meio, essas ações podem ser entendidas como define Souza (2005, p. 113): “o solapamento da qualidade de vida de uma coletividade na esteira dos impactos negativos exercidos sobre o ambiente". Ou seja, a queda da qualidade de vida, como consequência dos impactos acometidos sobre o meio. Ainda autores como Costa e Braga (op.cit, p. 4) discutem sobre a caracterização dos conflitos urbanos e ambientais como:

O campo de conflitos estruturado em torno da questão urbano-ambiental caracteriza-se por uma dinâmica intrincada de relações e disputas de poder que produz diferentes matrizes discursivas sobre cidade e meio ambiente e gera importantes limites à formulação e legitimação de diretrizes de política ambiental (COSTA; BRAGA, 2002, p.4).

Pode-se observar problemas e impactos decorrentes desse processo de evolução, utilizando-se como exemplo Mossoró, tais como: desmatamento desenfreado, construções e ocupações irregulares, falta de infraestrutura básica, déficit do saneamento ambiental, desigualdades sociais, especulação imobiliária, vulnerabilidade e deterioração dos sistemas naturais, problemáticas com o descarte de resíduos sólidos, abastecimento de água, excessos de propagandas e comunicações visuais (poluição visual), mobilidade populacional, descarga de efluentes as margens do Rio Apodi/Mossoró, aumento da frota de veículos automotivos, destruição do patrimônio histórico-arquitetônico, emissão de particulados, poluição sonora, diminuição da flora e fauna, conflitos sócio-econômicos, entre outros.

Portanto, percebe-se que as áreas urbanas do município de Mossoró estão crescendo e as áreas de periferias também, com forte concentração de problemas e riscos sociais e ambientais em determinadas localidades, além de condições socioeconômicas extremamente desfavoráveis para alguns, com baixos 
níveis de renda, escolaridade e saneamento ambiental, contribuindo para agravar o processo de risco e vulnerabilidade ambiental.

\section{PERCEPÇÕES SOBREAPROBLEMÁTICA SOCIOAMBIENTAL EXISTENTE}

Como já citado, anteriormente, a expansão urbana acelerada, sem planejamento e as pressões antropicas sobre os recursos naturais tem provocados riscos e o surgimento de zonas de vulnerabilidade socioambiental no município. Logo, faz necessário esclarecer que o termo vulnerabilidade é definido por Marandola Jr. e Hosan (2006, pág. 33) como:

Um fenômeno expressivo da modernidade tardia, característica da forma de enfrentar o perigo nas diferentes escalas. Penetrando em todos os campos da vida social, risco e incerteza tornaram-se palavras-chave para compreender as dinâmicas espaço-temporais contemporâneas, demandando um olhar abrangente da vulnerabilidade em sua multidimensionalidade inerente. O diálogo interdisciplinar é o caminho para a reflexão sobre suas dimensões (MARANDOLA JR.; HOSAN, 2006, pág. 33).
Já o risco surge a partir de diversos aspectos em uma mesma localidade, dentre eles os ecológicos, econômicos, geográficos, químicos, genéticos, nucleares, políticos, entre outros. Os riscos são considerados globais e surgem a partir de ações humanas criadas pela própria sociedade e, não a partir de desastres naturais ou forças religiosas, como muitos acreditam. Os riscos modernos escapam cada vez mais dos mecanismos de proteção e controle a eles designados (BECK, 2010).

Dentre as percepções e concepções acerca das problemáticas existentes no município, algumas delas são apresentadas por Oliveira Jr. e Grigio (2011) que consideram: a disposição irregular e deficiência no tratamento dos resíduos sólidos, lançamento de efluentes no rio Apodi-Mossoró, construções irregulares, falta de pavimentação e infraestrutura inadequada de ruas sem qualquer ordenação em algumas localidades (figura 02), implantação e lançamento de grandes empreendimentos habitacionais que acabam colaborando para a exclusão socioespacial e especulação imobiliária (figura 03), deficiência em áreas de lazer públicas que possam colaborar para uma melhor qualidade de vida, assim como o alto índice de violência e criminalidade presentes no município.

Figura 02. Falta de pavimentação e serviços de saneamento em área periférica do município de Mossoró - RN/Brasil.

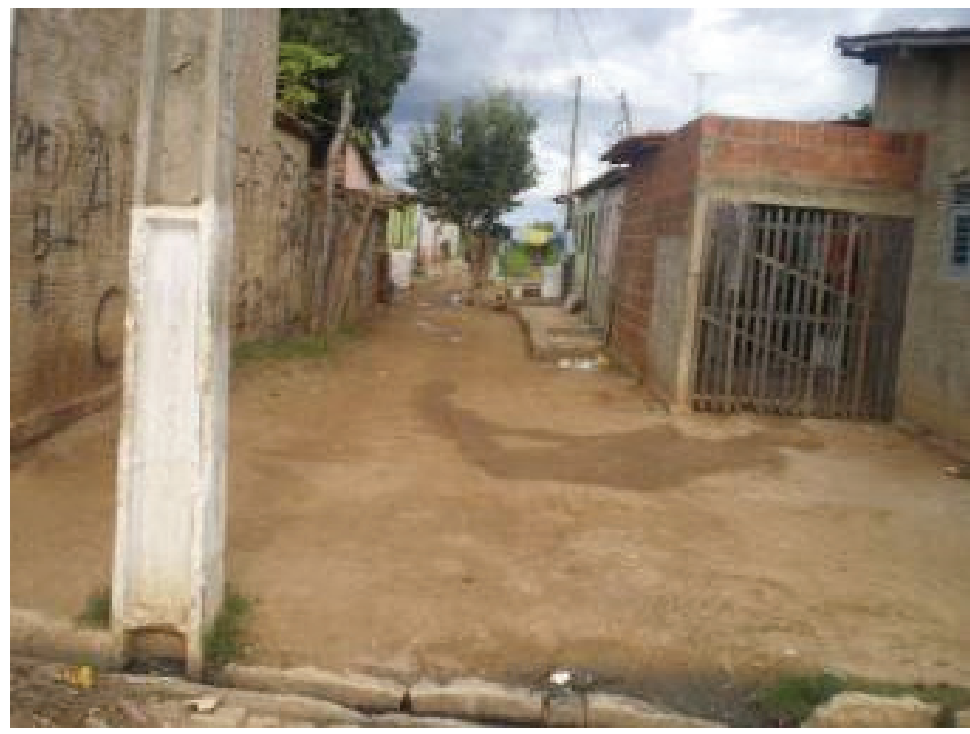

Fonte: Banco de imagens do NESAT, 2011 
Figura 03. Vista panorâmica do crescimento vertical e habitacional do município de Mossoró - RN/Brasil

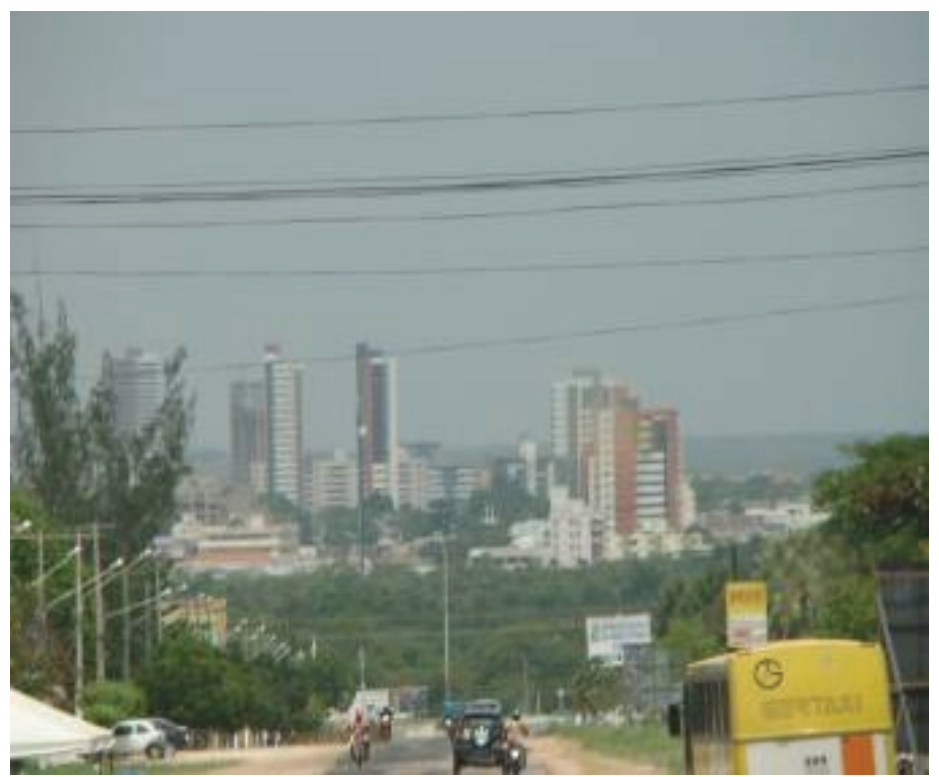

Fonte: Banco de imagens do NESAT, 2011.

No entanto, o que é visto e percebido nas cidades é um processo que se distancia dessa realidade, sobretudo em áreas de periferias. Marques (2005) aponta que falta de calçamento, pavimentação de ruas, saneamento ambiental; ausência de controle de enchentes e desse modo medidas para evitar os alagamentos, falta de serviços de saúde, ligações clandestinas de energia elétrica, ausência do recolhimento do lixo, dentre outros, são alguns dos problemas comumente encontrados nessas áreas. Como por exemplo, as construções irregulares em áreas de risco, criações de animais, supressão de vegetação nativa no decorrer das margens do rio Apodi-Mossoró, como também as margens do córrego localizado no bairro Redenção (figura 04) e ainda a deficiência no saneamento ambiental. Deve-se destacar que as atividades humanas vêm acelerando de forma vertiginosa os processos erosivos, já que o desmatamento e a devastação da vegetação nativa com o uso de técnicas inadequadas de utilização desse solo favorecem o aumento da erosão do solo.

Pode-se observar que "as áreas de degradação ambiental coincidem com as áreas de degradação social, sobrepondo perigos, muitas vezes potencializando outros riscos ou amplificando seus efeitos e danos" (TORRES, 2000 apud MARANDOLA JR.; HOSAN, 2006, pág. 34). Isso é perceptível na localidade, pois muitas dessas problemáticas aqui citadas estão presentes em bairros periféricos e mais longínquos do centro urbano ou das localidades que oferecem uma melhor infraestrutura urbana, com populações com menores poderes aquisitivos e vitimizadas com a deficiência de políticas publicas abrangentes e igualitárias. Como também ao processo de expansão urbana, que ao mesmo tempo em que se expande, desenvolve-se e gera renda, especula, desvaloriza, expulsa, segrega e compromete algumas localidades e indivíduos dentro do município. 
Figura 04. Construções irregulares em áreas de risco, criações de animais, falta de vegetação nativa, Mossoró - RN/Brasil.

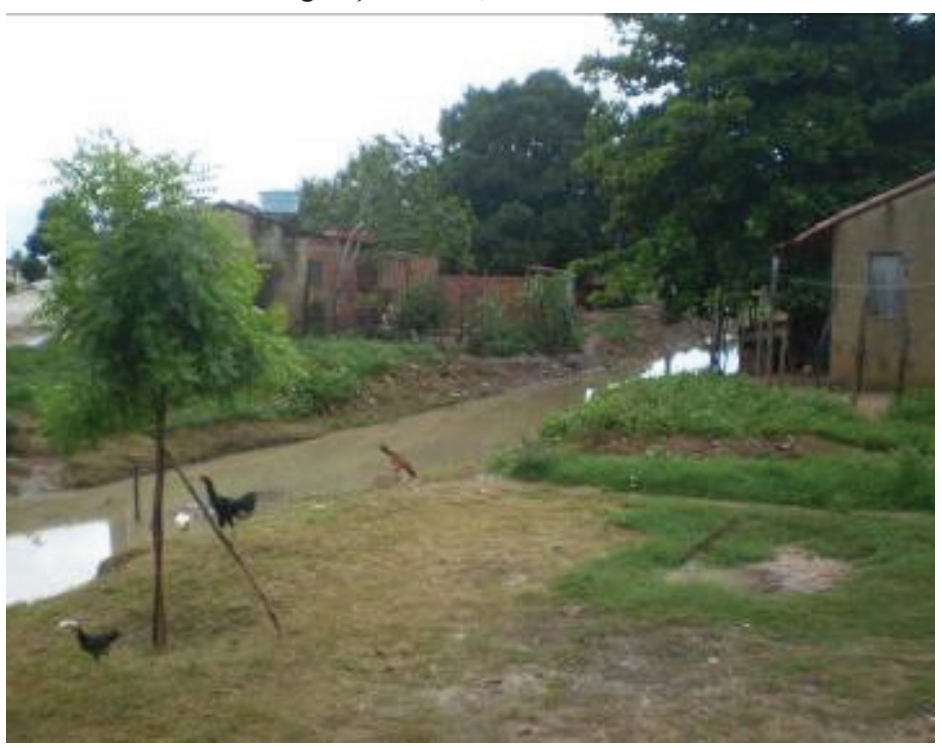

Fonte: Maria Clara Torquato Salles, 2011

Tratando-se da vulnerabilidade natural, a vegetação do município de Mossoró, o Centro de Sensoriamento Remoto (CSR) do Instituto Brasileiro de Meio Ambiente (IBAMA), 2010, realizou um levantamento sobre o nível de desmatamento da caatinga e apresentou que o referido município está na lista dos que mais sofreram desmatamento entre o período de 2002 a 2008, tendo como referência a área total original da Caatinga em cada município. Já que acordo com o (IBAMA, 2010) possui aproximadamente $2.110,62 \mathrm{~km}^{2}$ de área do município inserida dentro do "bioma caatinga". Apresentando uma área antropizada do bioma no referido período de $95 \mathrm{~km}^{2}$ e representando $4,51 \%$ de área de caatinga antropizada no município.

Para tanto, destaca-se neste estudo a importância da gestão ambiental, como um conjunto de ações destinadas à regular o uso, o controle e a proteção ambiental, em conformidade com os princípios estabelecidos nas políticas ambientais, tendo como resultado dessas ações o modelo de gerenciamento ambiental. Buscando um equilíbrio entre as relações sociais e ambientais existentes.

\section{NECESSIDADE DO PLANEJAMENTO URBA- NO MUNICIPAL}

Os estudos voltados para o planejamento e gestão ambiental têm considerado as orientações do desenvolvimento sustentável, buscando conciliar o víeis econômico, sociocultural e ambiental, visando o uso racional dos recursos naturais. Nessa perspectiva, a conservação e/ou preservação dos recursos naturais devem estar associadas ao planejamento, entendido aqui como um instrumento privilegiado de ações prospectivas para assegurar o direito a ambientes sustentáveis, preservar e conservar o patrimônio ambiental. É importante destacar que os objetivos, a estrutura, e os procedimentos de um planejamento são definidos a partir de um ideário norteador de todo o seu processo que levará conceitos e premissas de desenvolvimento, para um dado espaço num determinado tempo. (SANTOS, R. 2004)

O planejamento pode ser definido como um processo técnico instrumentado para transformar a realidade existente no sentido de objetivos previamente estabelecidos, sendo traduzido através de um plano. No tocante, ao planejamento ambiental, Santos R. (op. cit), menciona que todo ambiente necessita de um plano para desenvolver-se de maneira sustentável. Ao ampliar as considerações da referida autora, é possível afirmar que a zona costeira, composta de recursos que precisam ser utilizados de forma racional, deve ser planejada.

Portanto, Planejamento Ambiental, no espaço urbano, refere-se ao processo técnico voltados para 
áreas urbanas, visando criar condições de atender aos objetivos de um desenvolvimento, que considere as funções sociais, ambientais e dê garantia de bem-estar para a população que habita e/ou visita os centros urbanos. O reconhecimento das potencialidades econômicas do espaço urbano para a criação de alternativas social e ecologicamente sustentáveis em nosso país oferece uma instância privilegiada de reflexão e ação política ainda pouco explorada na literatura técnica sobre o desenvolvimento sustentável.

\section{CONCLUSÕES}

Os conflitos ambientais existentes nos centros urbanos não são problemáticas recentes, esses processos, na verdade, vem tomando maiores dimensões e ocorrências, e consequentemente uma maior percepção e tomada de conscientização por parte da população e dos gestores públicos para tratar e resolver essas problemáticas. Deve-se atentar para os processos de produção nos espaços urbanos e a emergência da regulação ambiental, principalmente, no que diz respeito à expansão urbana.

Os municípios devem buscar projetos e melhorias nas áreas urbanas, através de: Unidades de Conservação, fiscalização e monitoramento ambiental, práticas educativas para com a população, como a educação ambiental continua, efetividade nos planos de uso e regulação do solo urbano. Tornando-se imprescindível a busca e uso de caminhos apropriados dentro de um contexto socioambiental, principalmente, nos centros urbanos que sirvam como bases sólidas para dar suporte ao uso dos recursos naturais.

Ao tratar do município de Mossoró deve-se ressaltar que a "Metrópole do Futuro" e o verdadeiro município de Mossoró, possuem muitas diferenças que não foram e nem são evidenciadas pela mídia afora, já que muito dos fatos apresentados não condizem com a realidade. Pois, uma grande parte do município está esquecida e não se insere nessas apresentações. É evidente a necessidade de políticas públicas por parte da gestão municipal, centradas no desenvolvimento socioeconômico igualitário, e não apenas o favorecimento a uma seleta camada social, devendo focar as atividades em ações de suporte a educação, infraestrutura, segurança, a fim de, possibilitar um crescimento sustentável ao município objetivando alicerçar o terreno a absorver o "boom" desenvolvimentista detectado e comprovado no município.

Por outro lado observa-se que, transformações e investimentos significativos ocorreram e ocorrem ao longo dos anos no ambiente urbano, principalmente de cunho político e social. Já que vários desses conflitos ambientais ora apresentados e exemplificados poderiam ser evitados, desde que a solução para esses problemas também recaia sobre a sociedade e, por conseguinte, sua maior conscientização e também para o poder público através de políticas públicas e sociais públicas, assim como a maior efetividade em ações de monitoramento, fiscalização e punição a atividades e processos que possam comprometer a qualidade socioambiental do município.

Dentre esses processos destaca-se a importância de ser elaborado o zoneamento ecológico econômico do município de Mossoró que irá servir de instrumento de ordenação do território, auxiliando no planejamento territorial e possibilitando a harmonia das relações econômicas, sociais e ambientais que nele acontecem.

Portanto, considera-se que a aplicação de pesquisas que contemplem esses elementos é de suma importância para a melhor gestão e planejamento do território, sendo base para a formulação de políticas públicas mais eficazes. Além disso, que compreendam importantes auxílios na gestão sustentável dos recursos.

\section{REFERÊNCIAS}

BECK, U. Sociedade de Risco: Rumo a uma outra modernidade. Tradução de Sebastião Nascimento. São Paulo: Ed. 34. 2010.

BRASIL. Instituto Brasileiro de Geografia e Estatística - IBGE.Cidades@on line. Disponível em: < http://www.ibge.gov.br/cidadesat/topwindow.htm?1>, acesso em 04 julho de 2011.

COSTA, H. S. de M.; PEIXOTO, M. C. D. Dinâmica imobiliária e regulação ambiental: uma discussão a partir do eixo-sul da Região Metropolitana de Belo Horizonte. Rev. bras. estud. popul. [online]. 2007, 
vol.24, n.2, pp. 317-336. ISSN 0102-3098. doi: $10.1590 / \mathrm{S} 0102-30982007000200009$.

COSTA, H. S. de M.; BRAGA, T. M. Entre a conciliação e o conflito: dilemas para o planejamento e a gestão urbana e ambiental. In: X SEMINÁRIO SOBREA ECONOMIA MINEIRA, 2002, 24 p. (mimeo).

COUTINHO, L. A saída e o pós-sal. Revista Veja. São Paulo, ano 43, n. 35, ed. 2180, p. 110, 1 set. 2010.

DIAS, G. da M. Cidade sustentável: fundamentos legais, políticas urbanas, meio ambiente e saneamento básico. $1^{\circ} \mathrm{ed}$. Natal: Editora do Autor, 2009. 384 p.

MARANDOLA JR., E.; HOGAN, D. J. As dimensões da vulnerabilidade. Revista São Paulo em perspectiva. 2006, vol. 20, n.1, jan./mar. p. 33-43.

MARQUES, J. R. Meio ambiente urbano. Rio de Janeiro: Forense Universitária, 2005.

MINISTÉRIO DO MEIO AMBIENTE. Monitoramento do Bioma Caatinga 2002 - 2008. Instituto Brasileiro do Meio Ambiente e dos Recursos Naturais Renováveis - IBAMA e Centro de Informação, Documentação Ambiental e Editoração Luís Eduardo Magalhães - CID Ambiental. Brasília /DF, 58 p. 2010.

OLIVEIRA JR, H. S; GRIGIO, A. M. Mapa social: território e desigualdades - fase II Subprojeto: descrição, mapeamento e análise de risco sócioambiental do município de Mossoró - RN. Relatório de Pesquisa FAPERN/CNPq, 2011.

PREFEITURA MUNICIPAL DE MOSSORÓ. Secretarias. Disponível em: <http://www.prefeiturademossoro.com.br/secretarias.php $>$. Acesso em 04 julho de 2011.

ROCHA, A. P. B.. Expansão urbana de Mossoró (período de 1980 a 2004): geografia dinâmica e reestruturação do território. Natal-RN: EDUFRN Editora da UFRN, 2005. 292 p.
SANTOS, C. D. dos. A cidade de Mossoró, Rio Grande do Norte: processo de formação e produção do espaço urbano. Revista Mercator. 2009, vol.8, n.17, set./dez. p. 97-108.

SANTOS, R. F. dos. Planejamento ambiental: teoria e prática. 1. ed. São Paulo: Oficina de Textos, 2004. $184 \mathrm{p}$.

SOUZA, M. L. de. O desafio metropolitano: Um estudo sobre a Problemática Sócio-espacial nas Metrópoles Brasileiras. $2^{\circ}$. ed. Rio de Janeiro: Bertrand Brasil, 2005. p. 113 - 118.

SPENRANDIO, M. Onde o vento sopra a favor. Revista Veja. São Paulo, ano 44, n. 44, ed. 2241, p. 158-159, 2 nov. 2011.

\section{AGRADECIMENTOS}

O trabalho contou com apoio financeiro da CAPES-Brasil. 